\title{
Effects of polymer and bentonite support fluids on concrete-sand interface shear strength
}

\author{
C. LAM* ${ }^{*}$ S. A. JEFFERIS $\dagger$ and C. M. MARTIN
}

\begin{abstract}
Support fluids are widely used for the construction of deep bored piles and diaphragm walls. Specifications for the use of these fluids vary, and a thorough understanding of their effect on pile shaft resistance has not yet been developed. This paper presents the results of a set of concrete-sand interface shear tests carried out using both polymer and bentonite support fluids, with water as a reference fluid. It was found that polymer fluids had little effect on the interface shear strength when compared with water. Furthermore, in contrast to the results of earlier studies, concrete curing time was found to have little effect on the results. However, when bentonite slurry was used, the interface shear strength was found to decrease approximately linearly with the square root of the filtration time, until the strength of the pure filter cake was reached. This was due to the development of a bentonite filter cake at the interface so that only aggregate protruding through the filter cake made contact with the sand. It was found that the full concrete-sand shearing resistance could be mobilised when the concrete-sand contact area was greater than about $50 \%$ of the total area.
\end{abstract}

KEYWORDS: laboratory equipment; laboratory tests; piles; shear strength

\section{INTRODUCTION}

Bentonite support fluids have been used for the construction of diaphragm walls and bored piles since the pioneering work of Veder (1953). It is now known that in permeable soils such as sand and gravel, the stabilising mechanism involves the formation of a filter cake on the side walls. Cake formation may be assisted by rheological blocking that is, penetration of the slurry into the ground until the gel strength of the slurry acting over the penetrated area of soil particles is sufficient to prevent further slurry penetration. The bentonite filter cake is of relatively low permeability, so it reduces fluid loss into the ground and provides a membrane against which the hydrostatic pressure of the slurry can act, so stabilising the excavation (Nash, 1974). The formation of a filter cake is necessary for a stable excavation with bentonite slurry in permeable soils. However, for friction piles and barrettes, the filter cake creates an undesirable layer of soft interface material between concrete and soil, and can reduce the interfacial resistance. Fig. 1 shows a diaphragm wall panel constructed at a site in London, with the top few metres of the wall surface exposed. A layer of filter cake with adhering soil can be seen on the wall surface below the level of the guide wall.

Although many studies have been carried out to investigate the effect of bentonite filter cake on interface resistance, a definitive understanding has not yet been developed, and unsatisfactory pile performance continues to be reported. For example, Randolph (2003) described load test results of two bored piles constructed using bentonite fluids in Vietnam. The shaft resistance of the first test pile was below expecta-

Manuscript received 15 January 2013; revised manuscript accepted 27 September 2013.

Discussion on this paper is welcomed by the editor.

* School of Mechanical, Aerospace and Civil Engineering, The University of Manchester, Manchester, UK.

$\dagger$ Environmental Geotechnics Ltd, Banbury, UK; Department of Engineering Science, University of Oxford, Oxford, UK.

\$ Department of Engineering Science, University of Oxford, Oxford, UK tion, so several modifications were made to the construction procedure for the second pile, including: $(a)$ steps to reduce the delay between excavation and concreting; $(b)$ a reduction in the head of bentonite above river level; $(c)$ mechanical scarifying of the side wall prior to casting the pile. These measures were all aimed at reducing the thickness of the filter cake and were reported to have led to an improvement of about $30 \%$ in the shaft resistance. This case history poses questions as to whether such steps are also necessary for other projects, and if not, whether current specifications are already adequate for minimising the weakening effect of bentonite filter cake at the concrete-soil interface.

The current UK specification (Institution of Civil Engineers, 2007) requires that, for the construction of bored piles, concrete should be placed within $12 \mathrm{~h}$ of the start of the excavation. In the USA, there can also be a time requirement, but it is slightly differently specified. For example, Brown et al. (2010) recommend that the time during which the bentonite fluid is left undisturbed in a pile bore should be less than $4 \mathrm{~h}$. However, no such time restriction can be found in the foundation manuals of countries such as Canada and Hong Kong (Canadian Geotechnical Society, 2006; Geotechnical Engineering Office, 2006). The discrepancies between these requirements, or the lack of them, indicates that further work is needed to quantify the effect of fluid support time for better quality control.

This paper presents the results of a laboratory investigation into the effect of support fluids on the interface shear strength between sand and cast in situ concrete. A review of the relevant literature is first given, followed by a description of the equipment used and the test results. Both bentonite and polymer fluids were included in the test programme, with water as the control fluid. The main effects of interest were those of support fluid filtration time, concrete surface roughness and concrete curing period.

\section{PREVIOUS STUDIES}

Summary of existing results

Many laboratory studies have been carried out to investigate the effects of excavation support fluids on interface 


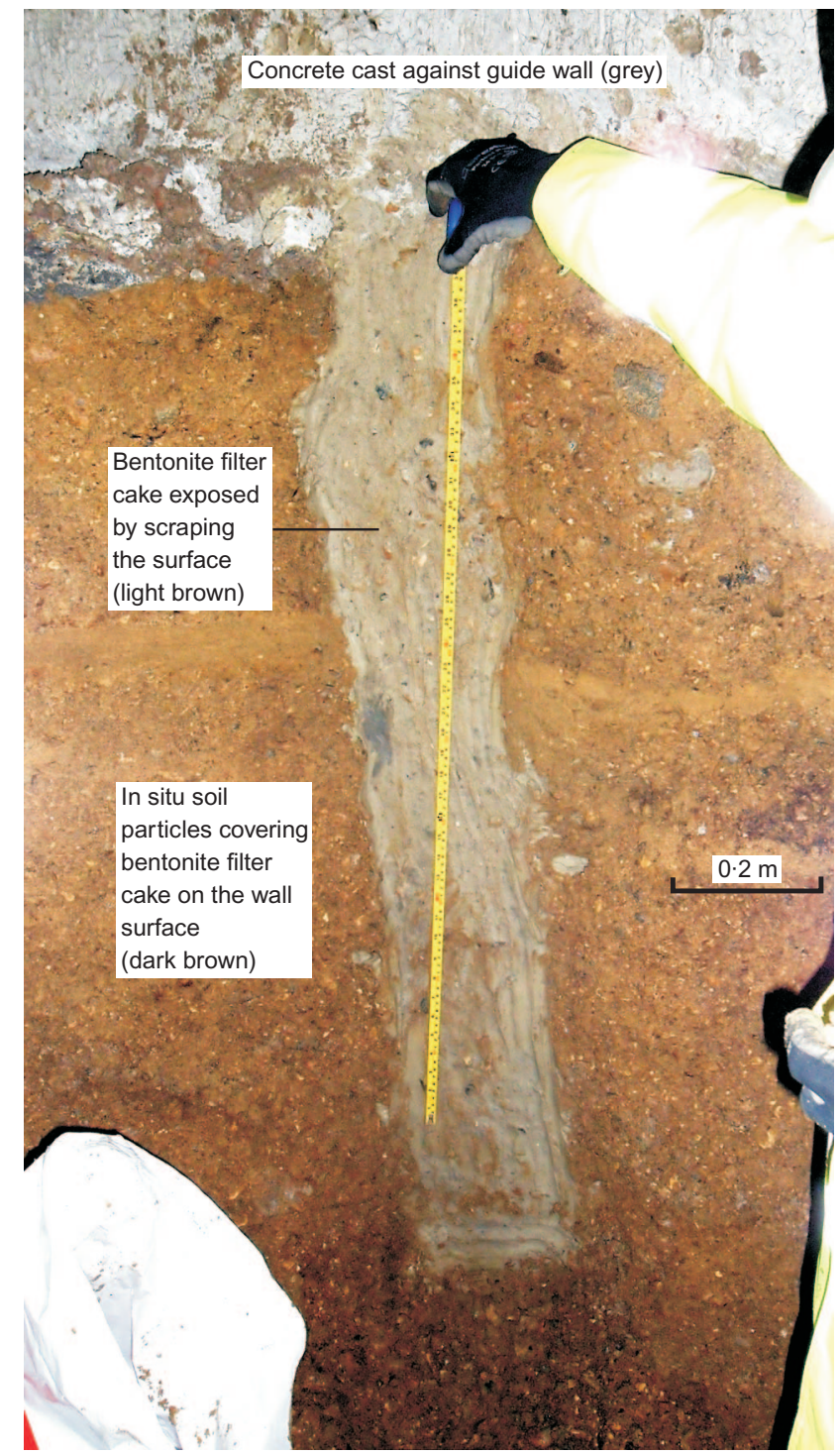

Fig. 1. Exposed bentonite filter cake on surface of diaphragm wall at site in London (courtesy of T. P. Suckling)

shear strength. Table 1 summarises the key results and the experimental techniques used. A brief critical review of these studies is given below.

At the outset it can be stated that almost all previous studies on the effects of bentonite slurry report a reduction in the interface shear strength compared with that for concrete in contact with a clean soil. However, the magnitude of the reported effect differs significantly. For example, Henry et al. (1998) reported that the interface strength of their specimens reduced to the strength of pure filter cakes after $6 \mathrm{~h}$ of filtration, but Cernak et al. (1973) found a similar effect only after $168 \mathrm{~h}$. The time-dependence of strength reduction is also unclear. For example, Cernak et al. (1973) and $\mathrm{Hu}$ et al. (2006) found that increasing the filtration time led to lower interface strength, but Majano et al. (1994) reported a V-shaped variation of strength with time (reduction followed by increase). Similarly, publications on the effects of polymer fluids report outcomes ranging from a noticeable reduction (Tawfiq \& Broughton, 1996; Shakir \& Zhu, 2010) to a significant improvement (Hu, 2003; $\mathrm{Hu}$ et al., 2006). These results do not provide a consistent baseline from which to establish and predict the effects of excavation fluids.

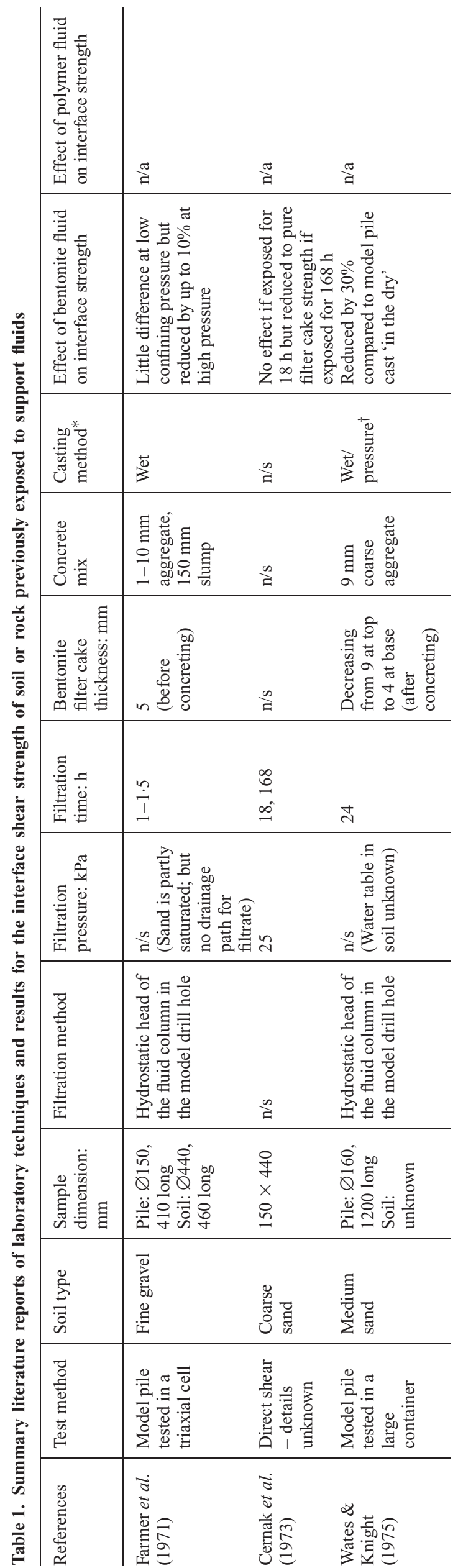



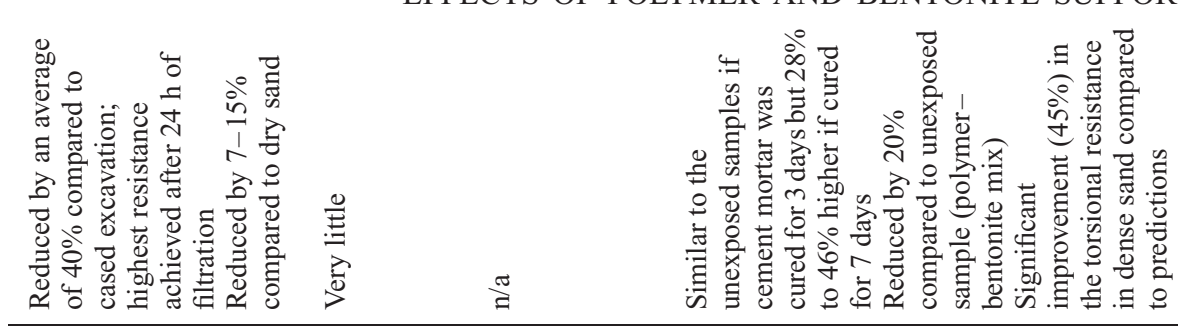

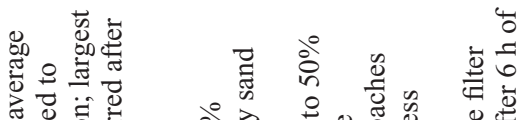

ส

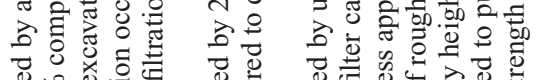

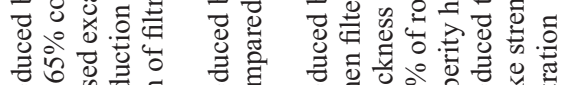

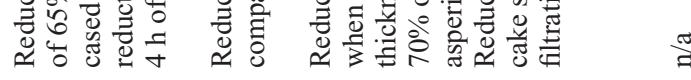

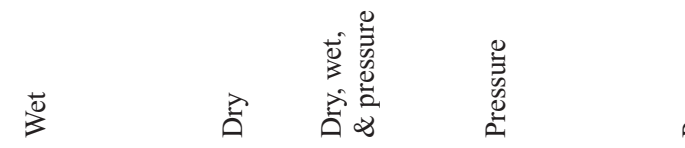

Min

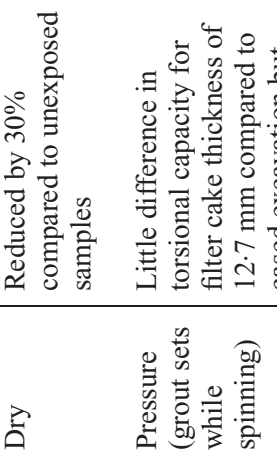

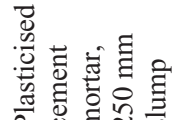

言

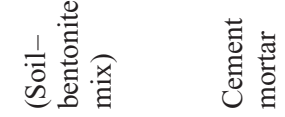

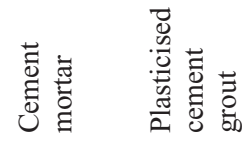

能

啒余

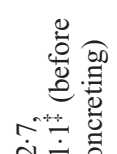

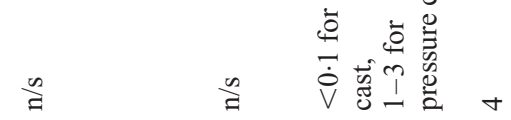

$\stackrel{\pi}{\Xi}$

莳

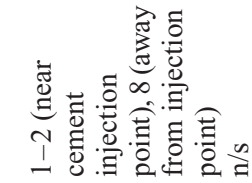

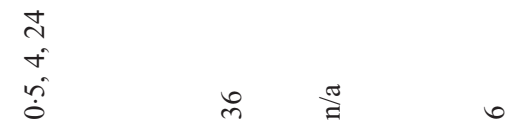

m

$\vec{\sim}$

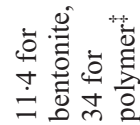

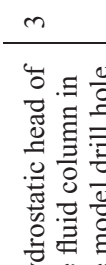

$\stackrel{\infty}{\Xi}$

m

$\stackrel{n}{z}$

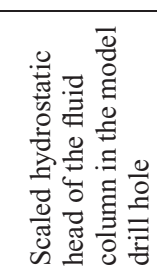

$\stackrel{4}{+1}$

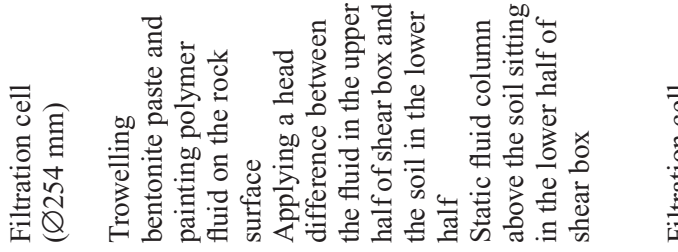

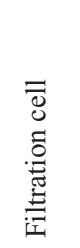

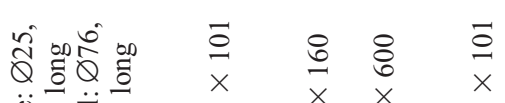

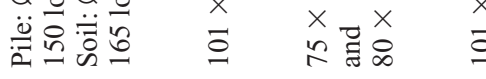

요

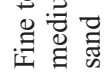

最重

高

敦

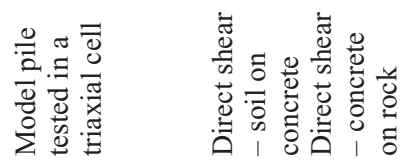

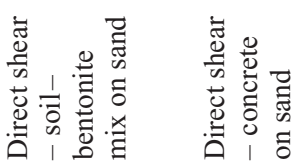

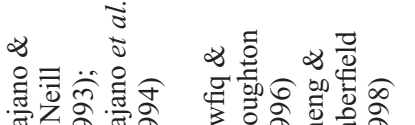

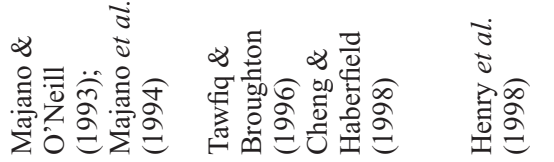

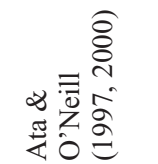

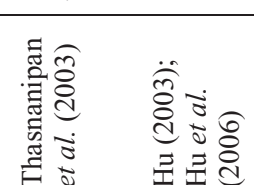

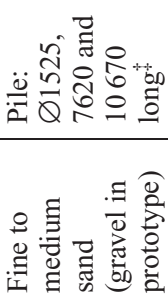

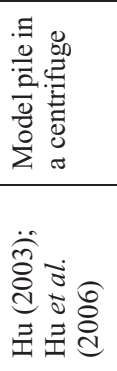

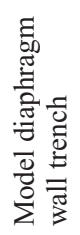

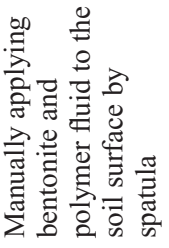

\&

8
品
$\times$
8
8

$\stackrel{\pi}{\sharp}$

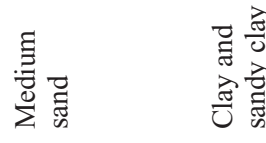

\begin{tabular}{|c|c|}
\hline 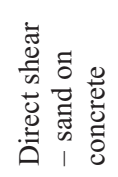 & 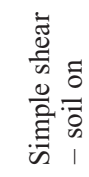 \\
\hline 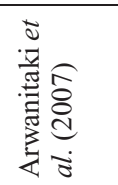 & 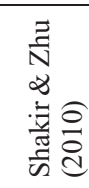 \\
\hline
\end{tabular}

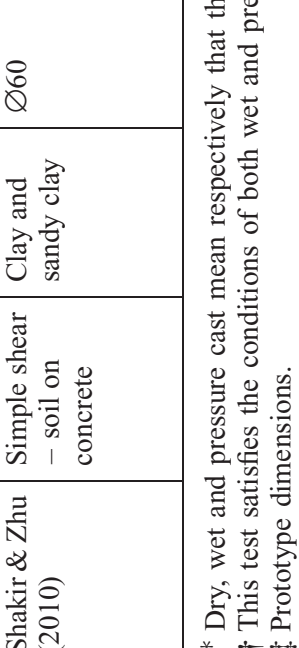




\section{Ideal test conditions}

Although some of the discrepancies between these previous results can be explained by the different properties of the materials used, many are actually attributable to the experimental techniques employed. Before discussing the individual investigations, it is useful to consider the 'ideal' conditions for laboratory interface shear tests involving support fluids.

(a) Filtration: the filtration pressure is the difference between the stabilising fluid pressure and the free-field pore-water pressure. It should correspond to that which is experienced in the field, and could range from $15-20 \mathrm{kPa}$ at sites with a high groundwater table to over $200 \mathrm{kPa}$ at depth in a soil with a low groundwater table.

(b) Concrete mix: the concrete mix design should be similar to that used in the field.

(c) Casting method: the concrete should be cast and cured under a wet concrete pressure representative of field conditions.

(d) Shearing procedure: the shearing rate should correspond to that of a typical field load test. According to the Institution of Civil Engineers (2007), this may range from an effective loading rate of approximately $3.7 \times 10^{-3} \%$ design verification load (DVL) per second (or 100\% DVL in $7 \cdot 5 \mathrm{~h}$ ) in a load-controlled maintained load test (MLT), to $0.01-0.02 \mathrm{~mm} / \mathrm{s}$ in a displacement-controlled constant rate of penetration (CRP) test.

\section{Evaluation of experimental techniques}

If the experimental techniques used in previous studies are judged against the above criteria, it is found that none of the studies satisfies all of them. First, most studies either did not report the filtration pressure, or only used a low pressure. In two cases, the filter cake was formed by manually plastering the soil or rock surface with a bentonite paste. Such a technique cannot properly replicate the field process of cake formation, and in particular the effect of time on filter cake thickness. Second, most studies either did not specify the concrete mix or used a cement mortar. This limits the possibility of investigating the effect of surface roughness - an important effect identified by Wates \& Knight (1975) and also in this research. Wates \& Knight used a concrete mix containing $9 \mathrm{~mm}$ coarse aggregate and found that the aggregate particles protruded from the concrete surface, which increased the surface roughness. Finally, fewer than half of the previous investigators cited in Table 1 cast and cured the concrete under an applied pressure. This procedure, termed 'pressure casting' by Cheng \& Haberfield (1998), is essential for the formation of a realistic interface.

In addition to the cake formation procedure and the type of concrete, differences in the test geometry are important. In the review of previous work it was found that all investigations, except for $\mathrm{Hu}$ et al.'s study which used a geotechnical centrifuge, either tested model piles in a pullout device or used an interface shear box (Hu et al., 2006). Although a centrifuge can simulate the soil stresses more realistically, it is not without problems. First, the effective sizes of the bentonite and soil particles are increased by a factor of $n$, where $\boldsymbol{n} \boldsymbol{g}$ is the centrifugal acceleration. This would result in the formation of a filter cake on a gravel side wall at the prototype scale (fine sand at model scale) but in fact under field conditions a filter cake can only form on the surface of a gravel bed following a rheological blocking process in the pores (Hutchinson et al., 1975; Jefferis, 1992). Second, in a centrifuge model, it is difficult to use any concrete mix other than a highly plasticised cement mortar to form the model pile, because of the constraints of centrifuge package size and the need to cast the pile in-flight. This limits the potential for modelling the important effect of aggregate protrusion.

The principal advantages of testing scale model piles in a pull-out device are that the geometry can be based on that of real piles, and the boundary stress conditions can be controlled. However, since the hydrostatic pressure in a model drill hole will be limited by the depth of the model hole, the filter cake cannot be formed under a representative pressure unless an external pressurisation device is used. Model piles tested in the laboratory typically suffer from the same size limitations as the centrifuge, and therefore use of a site-type concrete mix is not possible unless the diameter of the model pile is increased to about $150-200 \mathrm{~mm}$. However, if this is done, the size of the surrounding soil bed also needs to be increased, and the assembly can no longer be accommodated in a modified triaxial cell such as the one used by Majano et al. (1994).

Given the limitations of model pile test methods, it was concluded that the most appropriate equipment for the investigation of interface shearing is a purpose-designed shear box, as only the materials immediately at and adjacent to the interface are modelled. This can readily be done at 1:1 scale, as opposed to testing a whole pile but at a reduced scale. The specimen can therefore be kept reasonably small, while avoiding many of the limitations of the other methods. Therefore, an interface shear box with extended capabilities was designed and used to carry out the research described in this study.

\section{INTERFACE SHEAR BOX APPARATUS}

\section{Basic design and dimensions}

Figure 2 shows a photograph of the interface shear box apparatus. In essence, the apparatus developed for this study is a medium-sized shear box, the top half of which can first be filled with pressurised support fluid and then with fresh concrete. The plan internal dimensions are $175 \mathrm{~mm}$ by $275 \mathrm{~mm}$, the upper and lower halves of the box are respectively $100 \mathrm{~mm}$ and $70 \mathrm{~mm}$ high, and the gap between the two halves of the box is adjustable. These dimensions have no particular theoretical basis, but are simply chosen to enable the box to perform the required functions at a reasonable scale with respect to the $20 \mathrm{~mm}$ maximum aggregate size in the concrete (a maximum size common for piling concrete). For example, the top half of the box is large enough to act as a fluid reservoir during the filtration stage, and to accommodate a real concrete mix containing coarse aggregate.

As the concrete surface was expected to be rough due to aggregate protrusion, an interface gap height of $20 \mathrm{~mm}$ was used for the tests. This was achieved by the use of four steel spacer strips secured between the two halves of the box. The spacers form the middle part of a pressure vessel during the filtration and concreting stages, but can be removed to form the interface gap prior to the shearing stage of the test.

\section{Water saturation and support fluid filtration}

Figure 3(a) shows a schematic diagram of the apparatus during the water saturation and support fluid filtration stages. Unlike some previous investigations which used a separate filtration cell to form a filter cake (Tawfiq \& Broughton, 1996; Thasnanipan et al., 2003), the new design with a pressurised slurry box and a filtrate drain allows the filtration stage to take place with the test soil already seated in the lower half of the box. The test soil was first flushed with water with the bottom drainage port open, then flooded with either the bentonite or polymer support fluid (except for the 


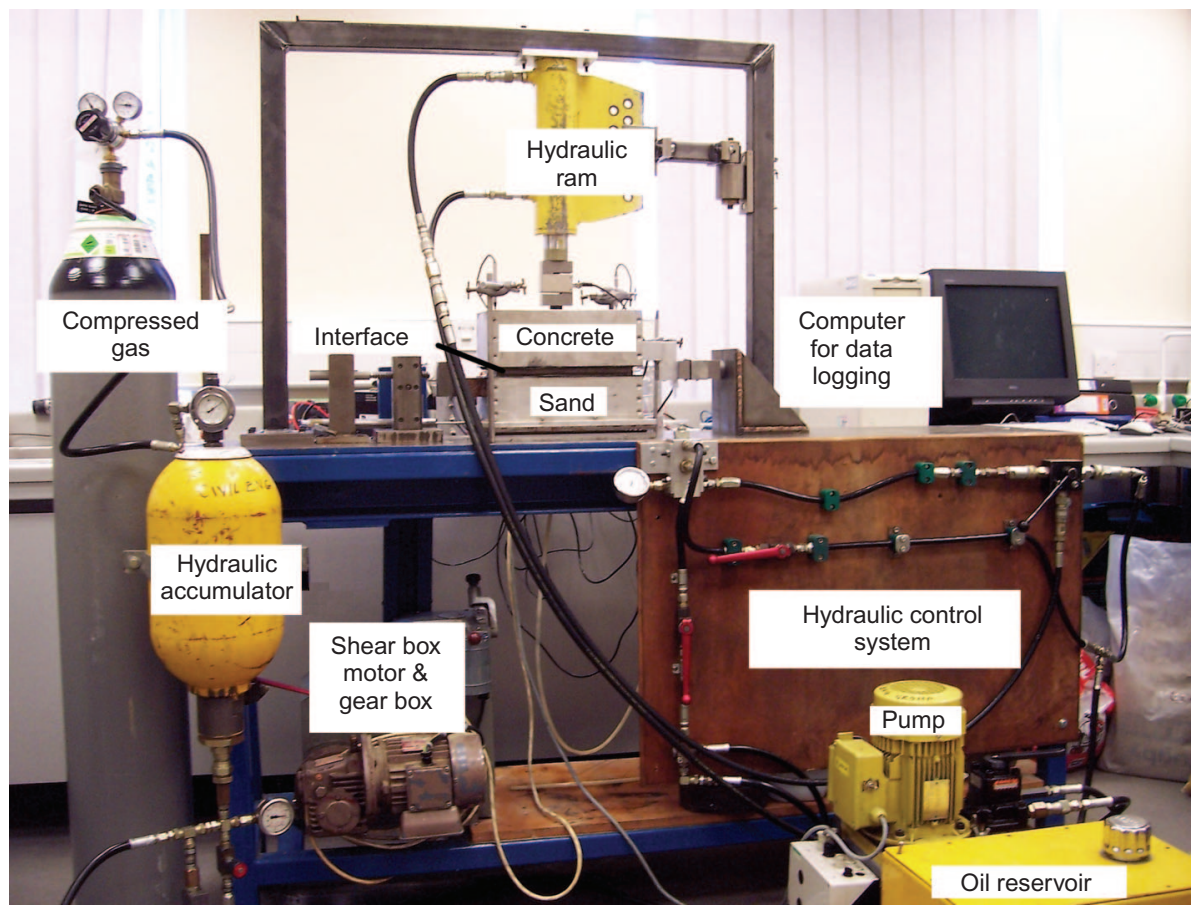

Fig. 2. Interface shear box apparatus

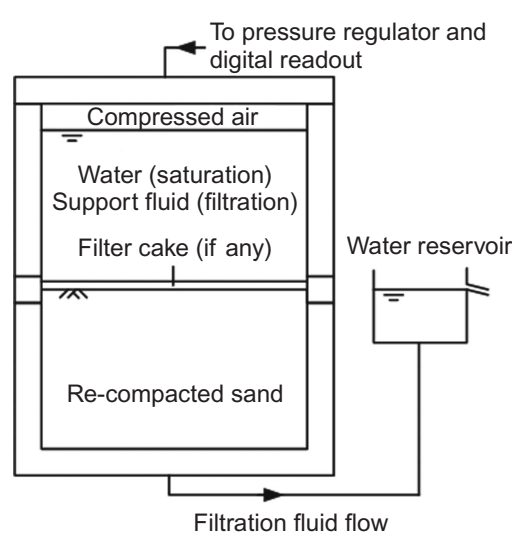

(a)

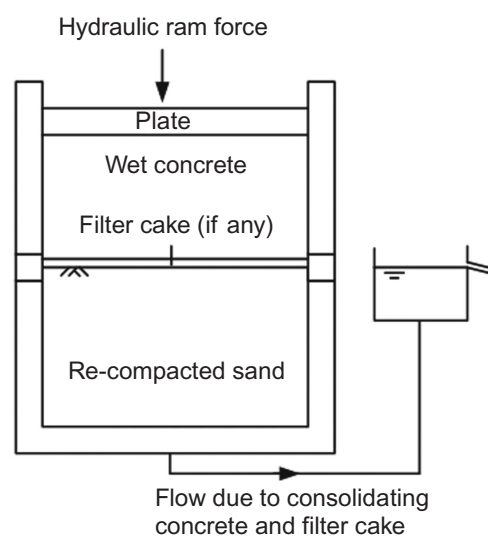

(b)

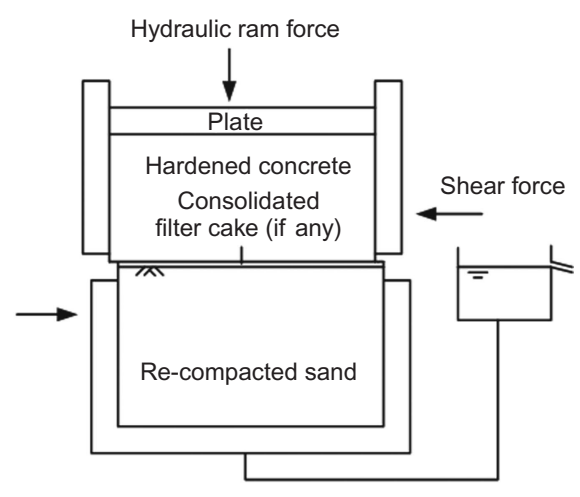

(c)

Fig. 3. Schematic diagrams showing arrangement of the interface shear box during: (a) soil saturation and support fluid filtration; (b) pressure casting and curing; (c) shearing

reference water test). The support fluid was then pressurised at the desired pressure. The benefit of this approach is that it reduces the need for sample movement and the potential for soil and filter cake disturbance. Ata \& O'Neill (1997, 2000) employed a similar arrangement but with a short fluid column, which provided only rather limited filtration pressures. The present design with a slurry box supplied with the support fluid by way of a hydraulic accumulator facilitated the use of much higher, more realistic pressures. This loading arrangement was also used by Peña Duarte (2007) to test highly compressible sand-foam mixtures.

\section{Concreting}

After the formation of a filter cake, the top of the cell was removed and the remaining fluid was siphoned off. The drainage port at the bottom of the box was left open, but the pipe was connected to an open-topped water reservoir in which the water level was set to match that of the top surface of the soil. This ensured that the soil remained fully satu- rated, and also allowed free water movement in and out of the soil during the subsequent concrete curing and shearing stages. The concrete, a superplasticised, self-consolidating mix (see Table 2), was then placed on top of the filter cake (if any) and then, as described below, cured under an appropriate wet concrete pressure. This procedure simulates field conditions in which the filter cake is formed undisturbed for a period of time but, importantly, is not scoured away by the rising column of wet concrete. It was believed that scouring of the filter cake by rising concrete does occur, but Farmer et al. (1971) and Wates \& Knight (1975) found the effect to be negligible to non-existent. The scouring that occurs during tremie casting will depend on the flow regime of the rising concrete (Littlechild \& Plumbridge, 1998) and the properties of the filter cake - a material which typically grades from bulk slurry to a tight clay material in contact with the trench wall. Soft slurry may be removed by the rising concrete but stiffer material is likely to persist unless previously removed by the mechanical action of a digging or cleaning tool. 
Table 2. Concrete mix design used for laboratory tests

\begin{tabular}{l|c|l}
\hline Constituent & Quantity: $\mathrm{kg} / \mathrm{m}^{3}$ & Remarks \\
\hline Cement & 405 & $\begin{array}{l}\text { Portland cement with } 30 \% \text { fly ash } \\
10-20 \mathrm{~mm} \text { Thames Valley uncrushed } \\
\text { Coarse } 20 \mathrm{~mm} \text { aggregate }\end{array}$ \\
& 668 & $\begin{array}{l}\text { agregate } \\
5-10 \mathrm{~mm} \text { Thames Valley uncrushed } \\
\text { Coarse } 10 \mathrm{~mm} \text { aggregate }\end{array}$ \\
& 316 & $0-5 \mathrm{~mm}$ sharp sand \\
Fine aggregate & 839 & Water/cement ratio $=0 \cdot 4$ \\
Water & 162 & Superplasticiser \\
Admixture & 3 & - \\
Density & 2393 & \\
\hline
\end{tabular}

\section{Concrete pressurisation and curing}

Figure $3(\mathrm{~b})$ is a diagram of the apparatus during the concrete pressurisation and curing stage. As shown, the normal pressure was provided by a hydraulic ram with the capacity to apply up to $800 \mathrm{kPa}$. This is sufficient to replicate most field situations, as for a $30 \mathrm{~m}$ deep fluidsupported excavation the wet concrete pressure should only be about $450 \mathrm{kPa}$, according to the prediction equation given by Lings et al. (1994). After the required curing period, the ram pressure could be adjusted to provide the required normal stress for the shearing tests. However, for the tests reported in this study the ram pressure was left unchanged, effectively assuming that the full concrete pressure was 'locked in' after the curing process. In the field, the validity of this assumption will depend, among other factors, on the degree of saturation of the soil surrounding the pile. If the soil is fully saturated, the pile concrete will expand during curing due to water absorption and the contact pressure will increase; the opposite will be true for soil holding little water in the pores (Lam \& Jefferis, 2012). In this study, the concrete was cured inside the box at a constant room temperature of $20^{\circ} \mathrm{C}$. The curing period was typically 7 days except for one test where the curing period was 3 days.

\section{Shearing}

Figure 3(c) is a diagram of the apparatus during the shearing stage. After the specified concrete curing period, the spacers between the top and bottom halves of the box were removed to form the interface gap. Any filter cake that was formed at the interface during the filtration stage could now be seen from the side. For the shearing test the lower half of the box was displaced at a constant rate of $2 \mathrm{~mm} /$ $\min (0.033 \mathrm{~mm} / \mathrm{s})$ until a maximum displacement of $15 \mathrm{~mm}$ was reached. This shearing rate is similar to that of a typical displacement-controlled (CRP) field test (Institution of Civil Engineers, 2007). At this rate, coarse-grained soils in the lower box will remain fully drained, but any bentonite filter cake that is present at the interface will be sheared undrained due to its significantly lower permeability (in the order of $10^{-10} \mathrm{~m} / \mathrm{s}$ according to Jefferis, 1992). It may be noted that Henry et al. (1998) used a shearing rate of $0.0025 \mathrm{~mm} / \mathrm{min}$ for their tests in an effort to ensure complete drainage of both the soil and the filter cake. The present tests could have been carried out at a similar rate, but there would have been a risk of drying of the filter cake as its outer surface was exposed by the removal of the spacers prior to shearing.

\section{TEST CONDITIONS AND MATERIAL PROPERTIES Test conditions}

For interface shear tests involving support fluids, no one set of test conditions applies to all cases since the material properties and pressures (pore water, support fluid, wet concrete) are all site specific. For this study, a site at Stratford in East London was used as a representative UK case. This site is located $0.5 \mathrm{~km}$ south-east of the Stratford International station and bored piles were installed down to $27 \mathrm{~m}$ below ground level. The ground conditions consist of $6.5 \mathrm{~m}$ of made ground, $13 \mathrm{~m}$ of Lambeth Clay and at least $14 \mathrm{~m}$ of Thanet Sand (Lam et al., 2010a). The groundwater table in the deep aquifer was reduced to about $30.5 \mathrm{~m}$ below ground level due to dewatering at the nearby Stratford International station box. The pore-water pressure in the Thanet Sand, over the length of the pile, was therefore zero. The bentonite fluid pressure within the pile bore was hydrostatic and was calculated using a fresh slurry density of $1.02 \mathrm{~g} / \mathrm{cm}^{3}$. The wet concrete pressure was calculated using the method proposed by Lings et al. (1994), in which the concrete pressure is assumed to have a simple bilinear profile and the point of the transition, known as the critical depth, is taken as one-third of the excavation depth. The average bentonite and concrete pressures for the pile section in the Thanet Sand layer were estimated to be 230 and $360 \mathrm{kPa}$ respectively. These values were used as the filtration and concrete curing pressures in the laboratory tests.

\section{Concrete properties}

Details of the concrete mix used for the tests are given in Table 2. This is an actual piling concrete mix as developed by a UK concrete supplier, containing a superplasticiser and designed to be self-consolidating. The maximum aggregate size is $20 \mathrm{~mm}$, which is typical for high-workability foundation concrete. The target slump of this mix is $175 \mathrm{~mm}$ (slump class S4) and the 28-day cube strength is about $50 \mathrm{MPa}$.

\section{Thanet Sand properties}

Samples of Thanet Sand were taken from the East London site. Based on a sieve analysis, the $D_{10}, D_{30}$ and $D_{60}$ particle sizes are $0 \cdot 07,0 \cdot 1$ and $0 \cdot 14 \mathrm{~mm}$ respectively. These sizes are fine enough to prevent any deep penetration of the bentonite fluid (Jefferis, 1992) but a filter cake will form as the permeability is relatively high $\left(\approx 2 \times 10^{-5} \mathrm{~m} / \mathrm{s}\right.$, determined by the constant head method on recompacted samples) compared with that of a bentonite filter cake (in the order of $10^{-10} \mathrm{~m} / \mathrm{s}$ ).

The shear strength parameters of the Thanet Sand were determined using both a standard shear box $(60 \mathrm{~mm} \times$ $60 \mathrm{~mm})$ and the extended interface shear box $(175 \mathrm{~mm} \times$ $275 \mathrm{~mm}$ ) working in sand-on-sand mode by filling the upper half with sand instead of concrete. The sand was compacted using a vibrating hammer to a dry density of $1400 \pm 25 \mathrm{~kg} / \mathrm{m}^{3}$. This corresponds to a relative density of $68 \pm 7 \%$ (the minimum and maximum dry densities of this sand have been 
determined as 1200 and $1520 \mathrm{~kg} / \mathrm{m}^{3}$ respectively). The peak angle of shearing resistance, $\phi_{\mathrm{p}}^{\prime}$, was found to be $36^{\circ}$ over the stress range of interest. Troughton (1992) also reported the same peak angle on recompacted samples from a site in Canary Wharf. According to Ventouras \& Coop (2009), the $\phi_{\mathrm{p}}^{\prime}$ of undisturbed Thanet Sand can range from $30^{\circ}$ to $39^{\circ}$ in triaxial tests.

\section{Polymer fluid properties}

The polymer used was a synthetic polymer system known as SlurryPro CDP supplied by KB International. First, $1 \mathrm{~kg} / \mathrm{m}^{3}$ of CDP base polymer was mixed at low shear for 45 min with water to which a small amount of potassium hydroxide had been added, which raised the $\mathrm{pH}$ to 11 . LA-1 thickener at a quantity of $0.08 \mathrm{~kg} / \mathrm{m}^{3}$ was then added to improve the viscosity of the fluid further. Other additives such as weighting and fluid loss control agents are available for challenging ground conditions but were not used in this study. The properties of the prepared fluid were determined using the test methods prescribed by the Federation of Piling Specialists (2006) and the results are given in Table 3 . There are currently no commonly accepted compliance values for polymers, so no comparison is made between the properties of bentonite slurry and the polymer fluid, although it may be noted that the polymer fluid did not form a filter cake and had a much higher fluid loss than the bentonite slurry. Discussion of the stabilisation mechanism of polymers, which Lam et al. (2010b) and Jefferis et al. (2011) explain is not by filter cake formation, is beyond the scope of this paper.

\section{Bentonite fluid properties}

The bentonite used was a sodium-activated bentonite known as Berkbent 163, a civil engineering grade product supplied by Tolsa UK and commonly used for foundation projects in the UK (e.g. Suckling et al., 2011). It was mixed with water at $40 \mathrm{~kg} / \mathrm{m}^{3}$ using a $5000 \mathrm{r} / \mathrm{min}$ laboratory mixer for $30 \mathrm{~min}$, allowed to hydrate for $24 \mathrm{~h}$, and then briefly remixed before use. The properties of the bentonite slurry were determined using the same methods as for the polymer fluid, and the results are included in Table 3 . It can be seen that its properties fulfil all the requirements of the Institution of Civil Engineers (2007) specification. The thixotropic property of this bentonite slurry can be found in the paper by Jefferis \& Lam (2012).

\section{Bentonite filter cake properties}

To aid the interpretation of the interface shear test results, the properties of the bentonite filter cake under the simulated field conditions of the East London site were studied. Filter cakes were formed in a standard filter press (American
Petroleum Institute, 2003) under the chosen filtration pressure of $230 \mathrm{kPa}$ and then consolidated uniformly under the estimated concrete pressure of $360 \mathrm{kPa}$. At the end of each stage, the thickness was measured and this was repeated over a range of the filtration times. The results are shown in Fig. 4. As expected, during the filtration stage, the thickness of the filter cake increased linearly with the square root of time (Nash, 1974) and the thickness reduced significantly when consolidated after the filtration stage. The consolidated cake thickness is of particular relevance to the shear box results.

INTERFACE SHEAR TEST RESULTS AND DISCUSSION

A total of nine interface shear tests were carried out; details are given in Table 4. The first test was a reference test performed on a water-saturated sample without any support fluid filtration. The remaining eight tests were carried out using either polymer or bentonite fluids under various test conditions. The objectives of the test programme were to investigate: $(a)$ the effects of polymer fluid and of concrete curing time; $(b)$ the effects of bentonite fluid following various filtration times; $(c)$ the effect of concrete aggregate protrusion through bentonite filter cakes.

\section{Effect of polymer fluid}

Figure 5 shows the shear stress-displacement curves for Tests 1 to 3 (with water and polymer at two concrete ages) as set out in Table 4. It can be seen that the three curves have similar peak values, although the water-saturated sample shows somewhat higher initial stiffness due to its slightly higher initial dry density $\left(1425 \mathrm{~kg} / \mathrm{m}^{3}\right)$ compared with the other two samples $\left(1389\right.$ and $\left.1396 \mathrm{~kg} / \mathrm{m}^{3}\right)$. The similar peak values shown by the polymer-saturated samples at the two

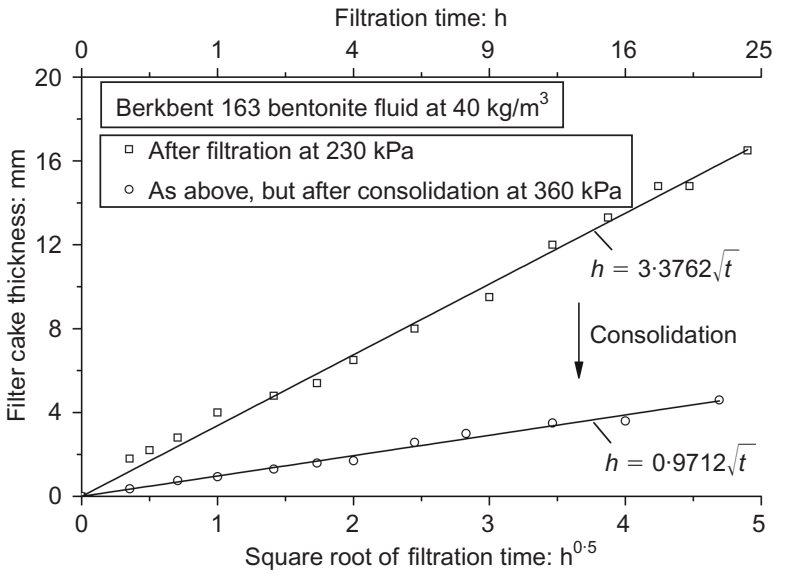

Fig. 4. Thickness of bentonite filter cakes as a function of square root of filtration time

Table 3. Properties of polymer and bentonite support fluids used for laboratory tests

\begin{tabular}{|c|c|c|c|c|c|}
\hline Property & Test method & Units & $\begin{array}{l}\text { Polymer test } \\
\text { results }\end{array}$ & $\begin{array}{l}\text { Bentonite test } \\
\text { results }\end{array}$ & $\begin{array}{l}\text { Compliance values for bentonite } \\
\text { fluid according to Institution of } \\
\text { Civil Engineers (2007) }\end{array}$ \\
\hline $\begin{array}{l}\text { Density } \\
\text { pH } \\
\text { Fluid loss at } 30 \mathrm{~min}^{*} \\
\text { Filter cake thickness at } \\
30 \text { min* }^{*} \\
\text { Marsh funnel viscosity } \\
10 \text {-min gel strength }\end{array}$ & $\begin{array}{l}\text { Mud balance } \\
\text { Electrical pH meter } \\
\text { Filter press } \\
\text { Micrometer } \\
\text { Marsh funnel } \\
\text { Fann viscometer }\end{array}$ & $\begin{array}{l}\mathrm{g} / \mathrm{cm}^{3} \\
- \\
\mathrm{ml} \\
\mathrm{mm} \\
\mathrm{s} \\
\mathrm{N} / \mathrm{m}^{2}\end{array}$ & $\begin{aligned} & 1 \cdot 00 \\
& 11 \cdot 0 \\
&>200 \\
& 0 \\
& 70 \\
& \approx 0\end{aligned}$ & $\begin{array}{l}1 \cdot 02 \\
10 \cdot 5 \\
26 \\
2 \cdot 5 \\
34 \\
5 \cdot 5\end{array}$ & $\begin{array}{c}<1 \cdot 10 \\
7-10 \cdot 5 \\
<30 \\
<3 \\
30-50 \\
4-40\end{array}$ \\
\hline
\end{tabular}

\footnotetext{
* Measured using the standard test pressure of $690 \mathrm{kPa}(100 \mathrm{psi})$.
} 
Table 4. List of interface shear box tests

\begin{tabular}{|c|c|c|c|c|c|}
\hline Test number* & Support fluid & Filtration time: $\mathrm{h}$ & $\begin{array}{l}\text { Max. aggregate size in } \\
\text { concrete: } \mathrm{mm}\end{array}$ & $\begin{array}{c}\text { Age of concrete at } \\
\text { test: days }\end{array}$ & Purpose of test \\
\hline 1 & Water & 0 & 20 & 7 & Reference \\
\hline 2 & Polymer & $7 \cdot 5$ & 20 & 3 & $\begin{array}{l}\text { To investigate the effects of } \\
\text { polymer fluid and of concrete } \\
\text { curing time }\end{array}$ \\
\hline 3 & Polymer & $7 \cdot 5$ & 20 & 7 & \\
\hline 4 & Bentonite & $0 \cdot 5$ & 20 & 7 & $\begin{array}{l}\text { To investigate the effect of } \\
\text { filtration time to bentonite fluid }\end{array}$ \\
\hline 5 & Bentonite & 3 & 20 & 7 & \\
\hline 6 & Bentonite & $7 \cdot 5$ & 20 & 7 & \\
\hline 7 & Bentonite & 12 & 20 & 7 & \\
\hline 8 & Bentonite & 24 & 20 & 7 & \\
\hline 9 & Bentonite & 12 & $5 \dagger$ & 7 & $\begin{array}{l}\text { To show the effect of concrete } \\
\text { mix }\end{array}$ \\
\hline
\end{tabular}

* Non-interface direct shear tests on Thanet Sand and bentonite filter cake are not included in this table.

$\dagger$ Microconcrete does not contain any coarse aggregate larger than $5 \mathrm{~mm}$.

Note: For all the tests, the sand was compacted to a dry density of $1400 \pm 25 \mathrm{~kg} / \mathrm{m}^{3}$ and the Stratford (East London) site conditions were simulated, that is a filtration pressure of $230 \mathrm{kPa}$ and wet concrete pressure of $360 \mathrm{kPa}$. The normal stress used during the shear test was also maintained at $360 \mathrm{kPa}$. The shear tests were carried out at a constant displacement rate of $2 \mathrm{~mm} / \mathrm{min}$.

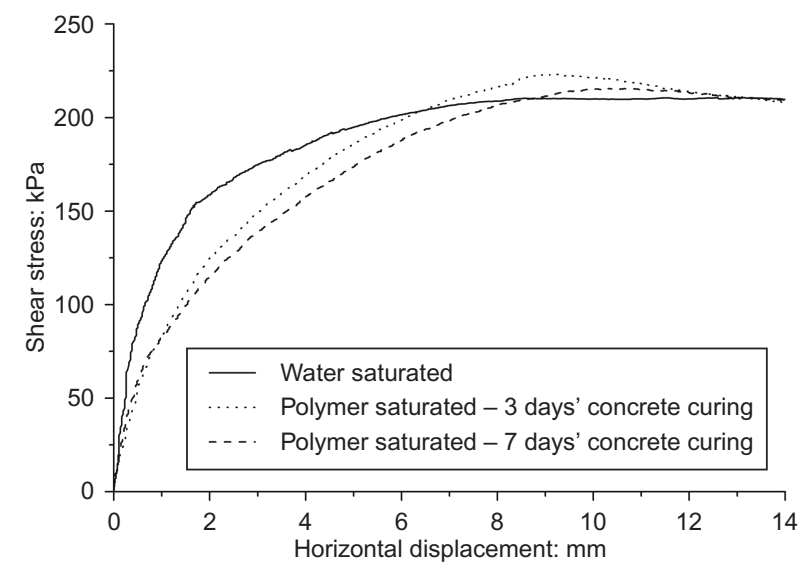

Fig. 5. Shear stress-displacement curves of Tests 1 to 3 showing the effects of polymer fluid and concrete curing time

concrete ages ( 3 and 7 days) are as expected because by 3 days the strength of the concrete $(\approx 30 \mathrm{MPa})$ already greatly exceeds the interface shear stress. However, the findings are contrary to the results of Ata \& O'Neill (2000), who found that samples cured for 7 days had higher shear strengths than those cured for 3 days. They attributed this to polymer fluid initially acting as a lubricant at the soil-cement mortar interface, but subsequently roughening the mortar surface by chemical reaction and causing the failure plane to develop in the sand rather than at the interface. However, as Tests 1 to 3 were carried out using a real piling concrete mix rather than a cement mortar, the surface was rough in all three cases due to aggregate protrusion and hence the failure plane was always in the sand. This explains why there is little difference between the three tests, but a significant difference from those of Ata \& O'Neill (2000). Fig. 6 shows a photograph of the concrete surface exposed after one of the polymer tests. The shear failure surface in the soil can be seen in the bottom half of Fig. 6.

\section{Effect of bentonite fluid}

Figure 7 shows the shear stress-displacement curves from Tests 1 (water and piling concrete), 4 to 8 (bentonite and piling concrete) and 9 (bentonite and microconcrete). The curve for a pure consolidated filter cake is also included for

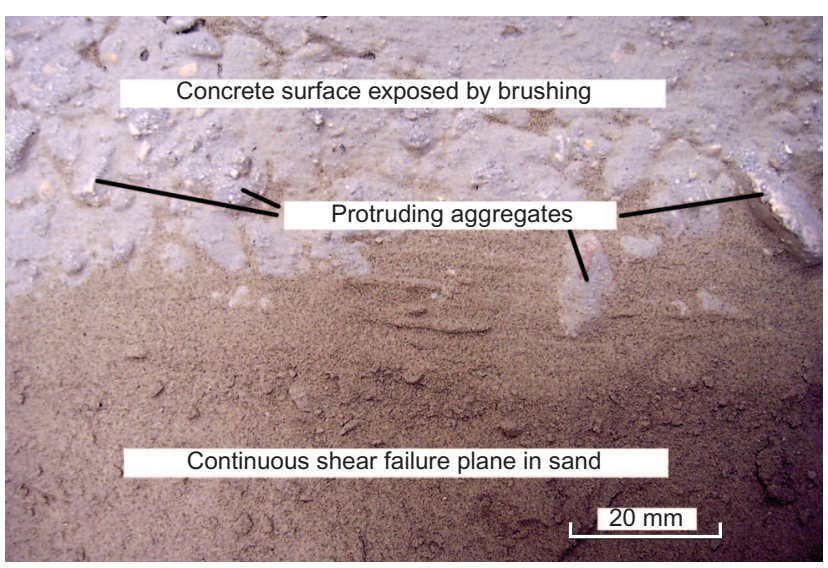

Fig. 6. Photograph showing exposed concrete surface (top) and shear failure plane (bottom) of an interface shear test using polymer support fluid

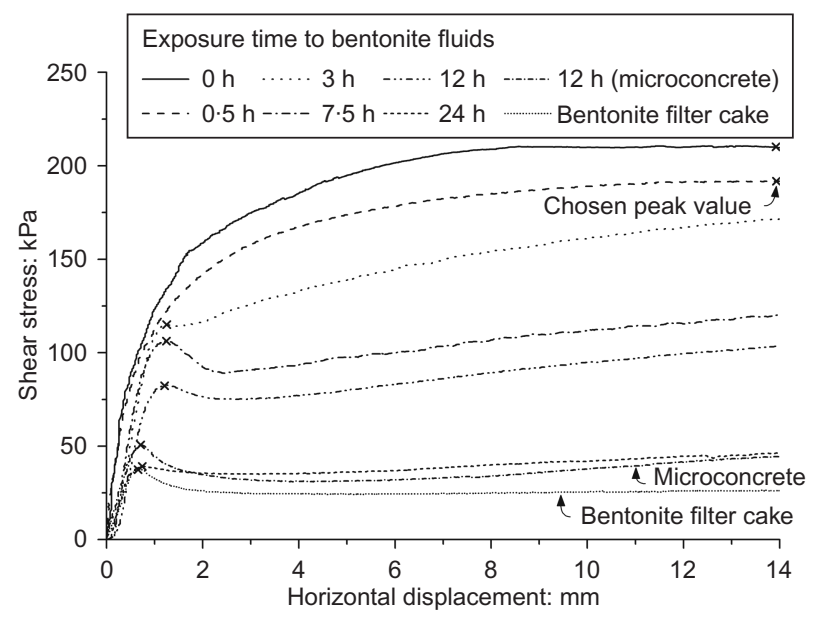

Fig. 7. Shear stress-displacement curves of Tests 1 and 4 to 9 showing effects of bentonite filtration time and concrete mix

comparison. It can be seen that the curve for the watersaturated sample (Test 1) forms the upper bound and the curve for the pure filter cake forms the lower bound, with the remainder plotting between them. It can also be seen that as the filtration time increases, the shearing resistance 
decreases, and that after $24 \mathrm{~h}$ of filtration the resistance approaches that of the filter cake. It is interesting to note that Henry et al. (1998) reported a similar finding but after only $6 \mathrm{~h}$ of filtration. This difference is possibly because Henry et al. did not use concrete but a soil-bentonite mix, and thus the effects of aggregate protrusion may have been more limited. Lastly, it can be seen that, for Tests 5 to 8 (3 to $24 \mathrm{~h}$ of filtration), the shearing resistance increased again after the initial peak - a behaviour also observed by Arwanitaki et al. (2007) in some of their direct interface shear tests. The post-peak rise seen in this study is believed to be an experimental effect, which is due to the sand resistance being mobilised by the slightly eccentric vertical load at large shear displacements. Had the tests been conducted in ring shear mode, the post-peak rise probably would not have occurred. As it is the initial peak strength that is of interest, the post-peak rise is ignored and the 'true' inferred peak values are marked by crosses on the plot. It is worth noting that Broms \& Hill (1973) also found a postpeak rise in the shaft resistance of a step-tapered pile, which was driven into a hole pre-drilled under bentonite slurry, and that no such behaviour was found in a similar pile installed in a hole formed with water. The reason for the post-peak rise in the first pile was probably the resistance of the sand being increasingly mobilised by the upper sections of the tapered pile at large displacements, at which point the shear strength of the filter cake had been overcome and was less significant.

Figure 8 summarises the peak shear stress results of Tests 1 to 8 . The peak shear stresses of recompacted Thanet Sand and of the filter cake are also shown as upper and lower bounds on the plot. It can be seen that for those samples subject to bentonite filtration, the interface shear strength reduces approximately linearly with the square root of the filtration time. This is because, as previously shown in Fig. 4 , the thickness of the filter cake also increases linearly with the square root of time. The practical implication is that when bentonite fluid is used to support an excavation in granular soils, the rate of filtration and hence the rate of interface strength reduction will be the greatest within the first few hours. The results in Fig. 8 may also explain why Brown (2002) found a pronounced strength reduction for bored piles (drilled shafts) which had only very limited exposure time to bentonite - a finding not expected by Brown at the time.

Comparison of the results in Fig. 8 with field data from various authors, which are plotted in Fig. 9, provides further support for the reported strength reduction effect. The shaft resistance results of Littlechild \& Plumbridge (1998) and Thasnanipan et al. (1998) are presented as ratios of actual to

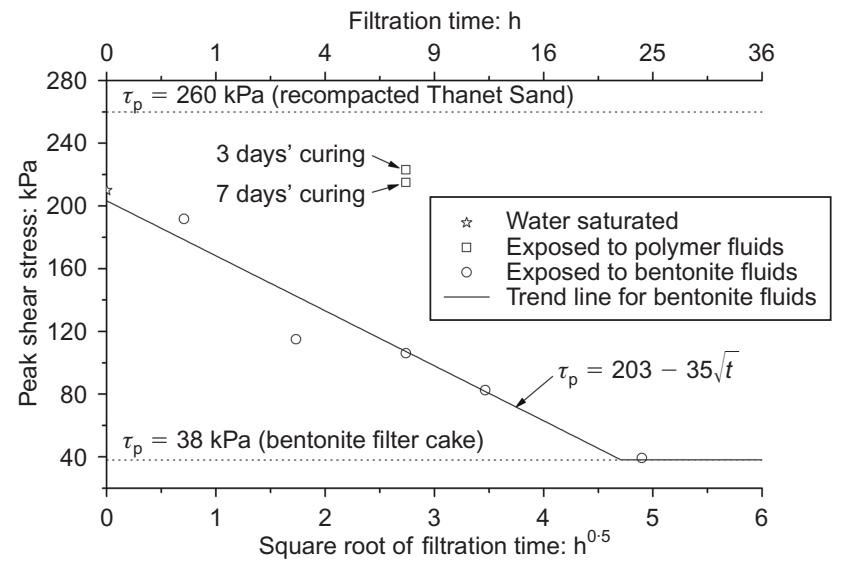

Fig. 8. Summary of peak shear stresses for Tests 1 to 8 using piling concrete

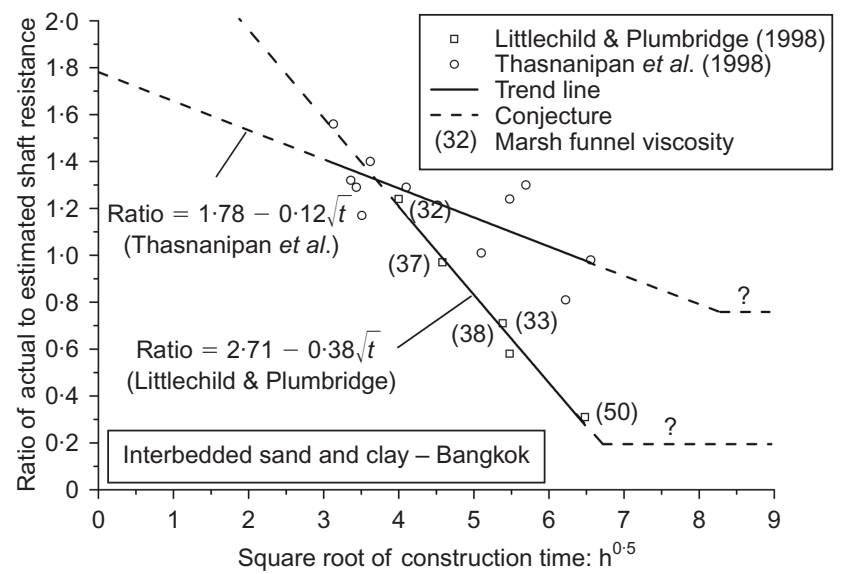

(a)

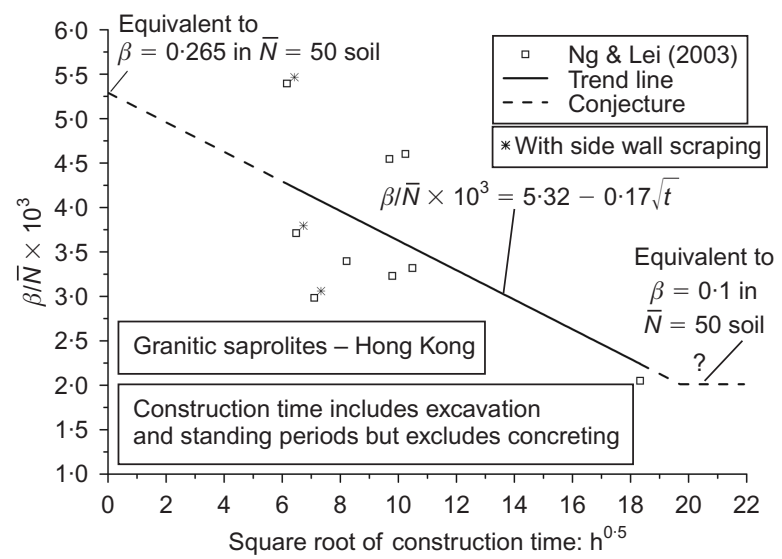

(b)

Fig. 9. Effect of construction time on shaft resistance: (a) data after Littlechild \& Plumbridge (1998) and Thasnanipan et al. (1998); (b) data after Ng \& Lei (2003)

estimated values, whereas those by $\mathrm{Ng} \&$ Lei (2003) are given as $\beta / \bar{N}$, where $\beta$ is ratio of maximum shaft resistance to mean effective vertical stress and $\bar{N}$ is the uncorrected mean standard penetration test (SPT) $N$ value. First, it is interesting to see that the two studies in Bangkok (Fig. 9(a)) give rather different results. Littlechild \& Plumbridge found that their results were influenced by both construction time and the Marsh funnel viscosity of the slurry, and hence the slope on the plot was exaggerated as the lowest viscosity $(32 \mathrm{~s})$ pile was built in the shortest time $(16 \mathrm{~h})$, while the highest viscosity $(50 \mathrm{~s})$ pile was built in the longest time (42 h). However, Thasnanipan et al., whose results include a larger data set, did not find any correlation with slurry viscosity; hence the values are not shown on the plot. Nevertheless, it is still worth mentioning that the time required to reach the postulated minimum strength is about $40-60 \mathrm{~h}$ in the first two cases (Fig. 9(a)) and $380 \mathrm{~h}$ in the third case (Fig. 9(b)), both of them being significantly longer than the $24 \mathrm{~h}$ found in the present laboratory tests. This is because during a real excavation the filter cake on the side wall can be removed or made thinner by the scraping action of the digging tool (depending on the bucket and tool design), and hence a longer construction time is required for a similar thickness of bentonite to be deposited. Deliberate side-wall scraping using specifically designed tools prior to concreting can greatly reduce this effect, as noted by Randolph (2003).

\section{Effect of aggregate protrusion}

To investigate the mechanism of strength reduction induced by a bentonite filter cake, the concrete surfaces of 
Tests 1 and 4 to 8 were examined after the tests. It was found that as the filtration time increased, the filter cake became thicker and fewer aggregate particles were able to penetrate through and make contact with the underlying sand, thus causing the concrete-sand contact area to decrease. To illustrate this, Fig. 10 shows photographs of the samples with $0 \cdot 5,3,12$ and $24 \mathrm{~h}$ of filtration. The concretesand contact area was assessed and is shown, as a fraction of the full area of the box (percentage), in the bottom righthand corner of each photograph.

To confirm the theory about aggregate protrusion, an additional test (No. 9) was carried out using microconcrete, which contained no aggregate larger than $5 \mathrm{~mm}$. The resulting shear stress-displacement curve is shown in Fig. 7. Comparing this curve with the curve for Test 7 (12 h filtration test for concrete made with $20 \mathrm{~mm}$ aggregate) indicates that the protrusion of the larger aggregate particles causes an increase of $63 \%$ in the peak interface shear stress. This effect must be purely due to the effect of surface roughness, as there were no other changes to test procedure. A visual examination of the concrete surfaces showed that when microconcrete was used, almost the entire surface was covered by the filter cake. This finding confirms that the development of shearing resistance in this type of 'sandwiched' system is controlled not only by the filter cake thickness but also by the surface roughness of the concrete, which is influenced by the maximum aggregate size in the concrete mix.

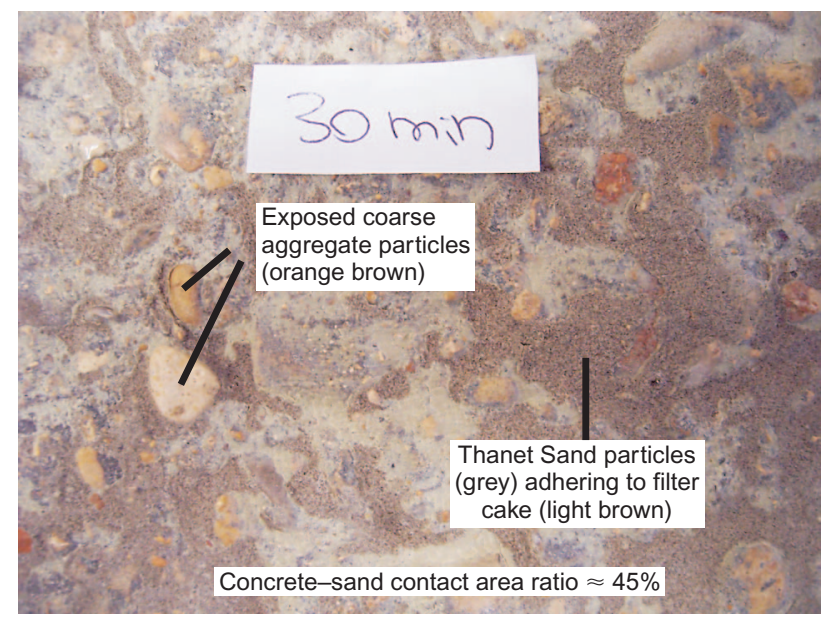

(a)

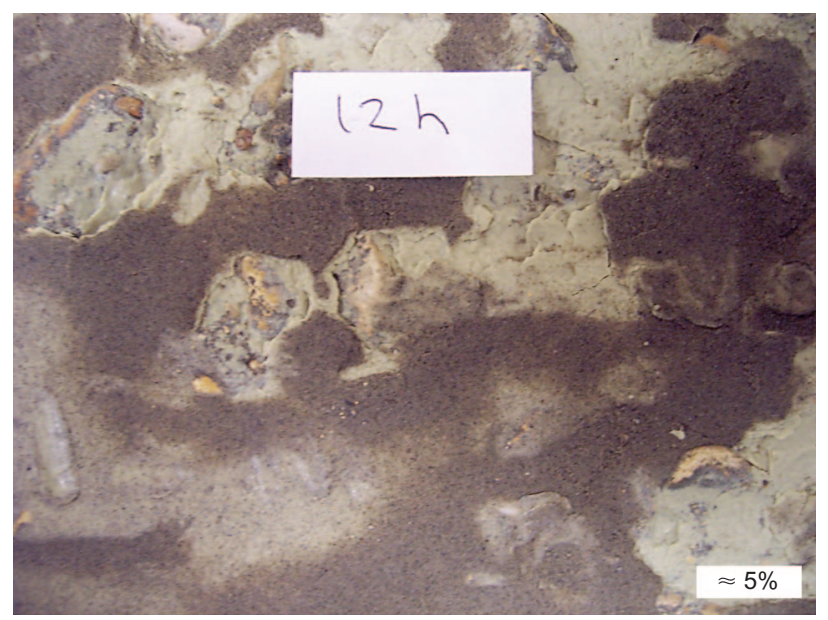

(c)
To quantify the effect of concrete-sand contact area, the peak strength values of Tests 1 and 4 to 9 were used to back-calculate a fractional concrete-sand contact area, $b$, using the following equation

$$
A \tau_{\mathrm{m}}=A b \tau_{\mathrm{c}-\mathrm{s}}+A(1-b) \tau_{\mathrm{c}-\mathrm{b}}
$$

which can be rearranged to

$$
b=\frac{\tau_{\mathrm{m}}-\tau_{\mathrm{c}-\mathrm{b}}}{\tau_{\mathrm{c}-\mathrm{s}}-\tau_{\mathrm{c}-\mathrm{b}}}
$$

where $A$ is full the cross-sectional area of the box, $\tau$ is the interface shear stress and subscripts ' $m$ ', ' $c-s$ ' and ' $c-b$ ' denote measured, concrete-to-sand and concrete-to-bentonite respectively. Based on the previous results, $\tau_{\mathrm{c}-\mathrm{s}}$ and $\tau_{\mathrm{c}-\mathrm{b}}$ have been determined as $210 \mathrm{kPa}$ and $38 \mathrm{kPa}$ respectively at the applied consolidation and test pressures. Fig. 11 plots the back-calculated area ratios, $b$, against the actual assessed ratios. It is interesting to see that the back-calculated values are about twice the actual values, meaning that for each percentage point increase in the concrete-sand contact area, the actual effect is about two percentage points. The proportion of contact area required to achieve the full concrete-tosand strength therefore appears to be only $50 \%$. This is probably because the protruding aggregate not only generates friction but also induces a ploughing action in the sand. When a sufficient amount of protruding aggregate is present, the shear plane will develop entirely in the sand.

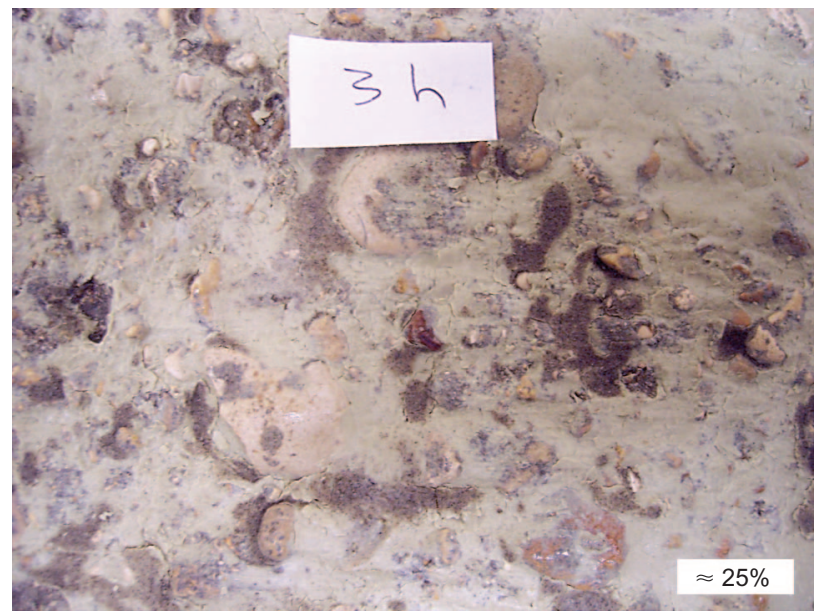

(b)

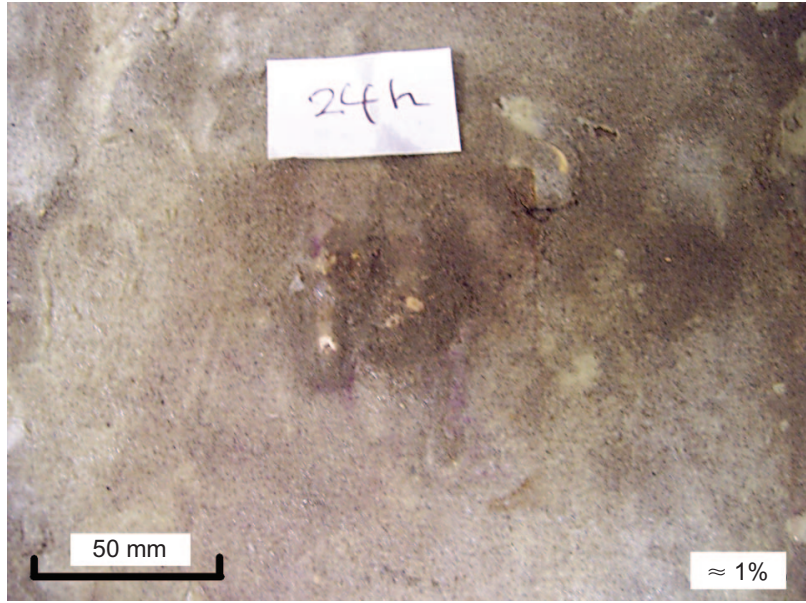

(d)

Fig. 10. Photographs of concrete surfaces showing the effect of filtration time on the fraction of the concrete-sand contact: (a) $0 \cdot 5 \mathrm{~h}$; (b) $3 \mathrm{~h}$; (c) $12 \mathrm{~h}$; (d) $24 \mathrm{~h}$ 


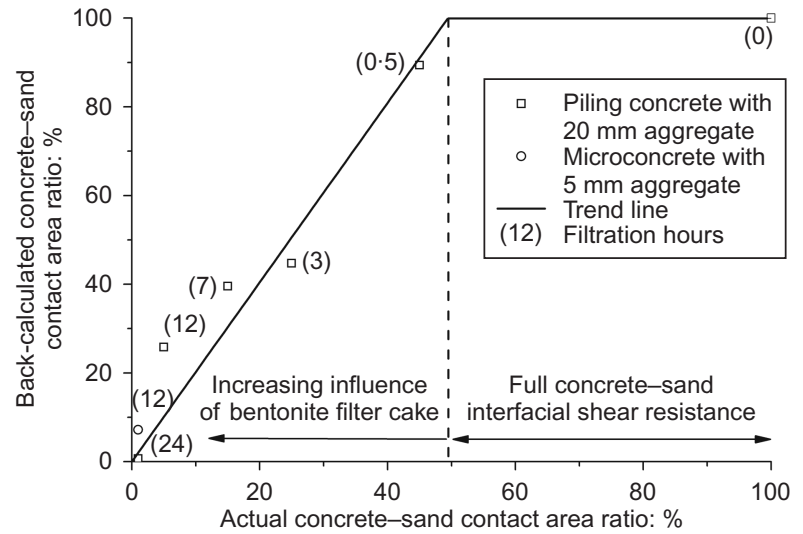

Fig. 11. Back-calculated plotted against actual fractional ratios of concrete-sand contact area

\section{CONCLUSIONS}

A series of laboratory tests has been carried out to study the effects of excavation support fluids on the interface shear strength between sand and cast in situ concrete. The main findings are as follows.

(a) The experiments show that, when compared to water, the presence of a polymer support fluid does not have a detrimental effect on the interface shear resistance, regardless of the age of the concrete. Field experience demonstrates that, unlike water, polymer fluids are capable of supporting sandy ground which would be liable to loosen and collapse in a water-filled excavation. This means that while the horizontal configuration of the shear surface is a valid means of testing the effect of polymer on shearing resistance of the sand-concrete interface, it is liable to overestimate the shearing resistance where water is used instead.

(b) Increasing the filtration time for bentonite fluid reduces the interface shear strength eventually, after about $24 \mathrm{~h}$ in the present experiments, to the shear strength of the filter cake. In a real excavation the interface shear strength will also depend on other factors such as the ground conditions, the properties of the bentonite slurry, the excavation tool used and whether the side wall is deliberately scraped after the completion of excavation and/or prior to cage insertion. It should be noted that in practice it may take a considerable time (typically $2-5 \mathrm{~h}$ ) for reinforcing cages to be inserted and concreting to be completed, hence even for a scraped side wall a perfect concrete-soil bond should not be expected for a pile formed under bentonite slurry. The strength reduction relationship shown in Fig. 8 might be used to represent the worst-case indicator where little or no side scraping is undertaken or where there is a significant delay between the end of excavation or scraping and the start of concreting.

(c) A major implication of the test results is that, when bentonite is used, the degree of strength reduction depends on both the thickness of the consolidated filter cake and the amount of aggregate protruding through the filter cake into the soil. At present none of these effects is explicitly considered in common pile design approaches, although the effect of construction time is acknowledged in some textbooks (e.g. Tomlinson, 2001). The laboratory results indicate that only $50 \%$ (by area) of concrete-sand contact is required to mobilise the full concrete-sand interface shear strength. This is thought to be due to the ploughing resistance developed by aggregate protruding into the sand. (d) In view of the above findings, it would appear that polymer-based support fluids provide an attractive alternative to conventional bentonite slurry, as they do not form a layer of soft filter cake at the pile-soil interface. The effect of different support fluids in silts and clays remains to be investigated. Based on the experience with polymer fluids so far, pile bore stability is usually not a problem provided the fluid is properly maintained on site (e.g. Jefferis \& Lam, 2013). It can be expected that polymer fluids will play a much larger role in the foundation industry in the future as their use continues to increase around the world.

(e) Although this paper is focused on maximising the interface shear strength in piles, the findings will have relevance to situations where there is a need to reduce interface shear strength, such as lubrication of pipes in pipe jacking works.

\section{ACKNOWLEDGEMENTS}

This research project was funded by the Engineering and Physical Sciences Research Council; grant reference nos. EP/C537815/1 (industrial CASE award) and EP/H50026X/1 (knowledge transfer secondment). The authors would like to thank Mr Bob Sawala for manufacturing the test apparatus and Miss Holly Bower for her participation in the preliminary trials. The materials used in this study were collected from construction sites of Balfour Beatty Ground Engineering with the kind permission of Messrs Tony Suckling and Viv Troughton. Additional polymer materials were provided by KB International courtesy of Messrs Ken and Gif Goodhue.

\section{NOTATION}

$A$ cross-sectional area of the interface shear box

$b$ calculated fractional area of concrete-sand contact surface

$D_{x} \quad$ particle size at which $x \%$ of the grains are smaller

$\bar{N}$ uncorrected mean SPT $N$ value

$n$ centrifugal acceleration factor

ng centrifugal acceleration

$\beta$ ratio of maximum shaft resistance to mean effective vertical stress

$\delta^{\prime} \quad$ interface friction angle

$\tau$ interface shear strength

$\tau_{\mathrm{c}-\mathrm{b}}$ interface shear strength, concrete to bentonite

$\tau_{\mathrm{c}-\mathrm{s}}$ interface shear strength, concrete to sand

$\tau_{\mathrm{m}}$ interface shear strength, measured

$\phi_{\mathrm{p}}^{\prime}$ peak angle of shearing resistance

\section{REFERENCES}

American Petroleum Institute (2003). Recommended practice for field testing water-based drilling fluids, API recommended practice 13B-1, 3rd edn, ANSI/API 13B-1/ISO 10414-1. Washington DC, USA: American Petroleum Institute.

Arwanitaki, A., König, D. \& Triantafyllidis, T. (2007). Zum Kontaktverhalten zwischen suspensionsgestützten Ortbetonwänden und dem anstehenden Boden. Bautechnik 84, No. 11, 781-792 (in German).

Ata, A. \& O'Neill, M. (1997). Characterization of the effect of POLY-BORE polymer on the construction and performance of drilled shaft foundations. Phase II: laboratory investigations. Houston, TX, USA: University of Houston.

Ata, A. \& O'Neill, M. (2000). The physicochemical interaction between PHPA polymer slurry and cement mortar. Geotech. Test. J. 23, No. 2, 225-235.

Broms, B. B. \& Hill, L. (1973). Pile foundations for the Kuwait Towers. Proceedings of the 8th international conference on soil mechanics and foundation engineering, Moscow, vol. 2, pp. $33-38$.

Brown, D. (2002). Effect of construction on axial capacity of drilled 
foundations in Piedmont soils. J. Geotech. Geoenviron. Engng 128, No. 12, 967-973.

Brown, D. A., Turner, J. P. \& Castelli, R. J. (2010). Drilled shafts construction procedures and LRFD design methods, Report FHWA NHI-10-016. Washington, DC, USA: National Highway Institute, US Department of Transportation, Federal Highway Administration.

Canadian Geotechnical Society (2006). Canadian foundation engineering manual, 4th edn. Richmond, BC, Canada: Canadian Geotechnical Society.

Cernak, B., Dvorak, A., Hlavacek, J., Klein, K. \& Petrasek, J. (1973). New approaches to problems of bearing capacity and settlement of piles. Proceedings of the 8th international conference on soil mechanics and foundation engineering, Moscow, vol. 2, pp. 67-74

Cheng, F. \& Haberfield, C. M. (1998). Laboratory study of the effect of drilling fluids on piles socketed into soft rock. Proceedings of the 2nd international symposium on the geotechnics of hard soils-soft rocks, Naples, vol. 1, pp. 93-101.

Farmer, I. W., Buckley, P. J. C. \& Sliwinski, Z. (1971). The effect of bentonite on the skin friction of cast in-place piles. Behaviour of Piles: Proceedings of conference organised by the Institution of Civil Engineers, London, pp. 67-72. London, UK: Institution of Civil Engineers.

Federation of Piling Specialists (2006). Bentonite support fluids in civil engineering, 2nd edn. Kent, UK: Federation of Piling Specialists.

Geotechnical Engineering Office (2006). Foundation design and construction, Publication 1/2006. Hong Kong SAR, China: Geotechnical Engineering Office.

Henry, L. B., Filz, G. M. \& Davidson, R. R. (1998). Formation and properties of bentonite filter cakes. Proceedings of the ASCE annual convention: Filtration and drainage in geotechnical/ geoenvironmental engineering, Boston, ASCE Geotechnical Special Publication No. 78, pp. 69-88. Reston, VA, USA: ASCE.

$\mathrm{Hu}, \mathrm{Z}$. (2003). Determining the optimum depth of drilled shafts subject to combined torsion and lateral loads in saturated sand from centrifuge testing. Master's dissertation, University of Florida, Gainesville, FL, USA.

Hu, Z., McVay, M., Bloomquist, D., Herrera, R. \& Lai, P. (2006). Influence of torque on lateral capacity of drilled shafts in sands. J. Geotech. Geoenviron. Engng., ASCE 132, No. 4, 456-464.

Hutchinson, M. T., Daw, G. P., Shotton, P. G. \& James, A. N. (1975). The properties of bentonite slurries used in diaphragm walling and their control. Proceedings of conference on diaphragm walls and anchorages, London, pp. 33-39. London, UK: Institution of Civil Engineers.

Institution of Civil Engineers (2007). ICE specification for piling and embedded retaining walls. London, UK: Thomas Telford.

Jefferis, S. A. (1992). Grouts and slurries. In Construction materials reference book (ed. D. K. Doran), pp. 48/1-48/24. Oxford, UK: Butterworth-Heinemann.

Jefferis, S. A. \& Lam, C. (2012). Letter to the Editor: Hydraulic characteristics of bentonite cake fabricated on cutoff walls. Clays Clay Miner. 60, No. 6, 557-560.

Jefferis, S. A. \& Lam, C. (2013). Polymer support fluids: use and misuse of innovative fluids in geotechnical works. Proceedings of the 18th international conference on soil mechanics and geotechnical engineering, Paris, vol. 4, pp. 3219-3222.

Jefferis, S. A., Troughton, V. \& Lam, C. (2011). Polymer systems for fluid supported excavations. In Geotechnical issues in construction: short paper series and proceedings of 2 nd conference, London, Report No. X513, pp. 7-12. London, UK: CIRIA.

Lam, C. \& Jefferis, S. A. (2012). Reply to the discussion by Fellenius on 'Critical assessment of pile modulus determination methods'. Can. Geotech. J. 49, No. 5, 622-629.

Lam, C., Troughton, V., Jefferis, S. \& Suckling, T. (2010a). Effect of support fluids on pile performance - a field trial in east London. Ground Engng 43, No. 10, 28-31.

Lam, C., Jefferis, S. A. \& Goodhue Jr, K. G. (2010b). Observations on viscosity reduction of PHPA polymer support fluids. Proceed- ings of sessions of the GeoShanghai 2010 international conference, Shanghai, ASCE Geotechnical Special Publication No. 205, pp. 184-191. Reston, VA, USA: ASCE.

Lings, M. L., Ng, C. W. W. \& Nash, D. F. T. (1994). The lateral pressure of wet concrete in diaphragm wall panels cast under bentonite. Proc. Instn. Civ. Engrs - Geotech. Engng 107, No. 3, $163-172$.

Littlechild, B. \& Plumbridge, G. (1998). Effects of construction technique on the behaviour of plain bored cast in situ piles constructed under drilling slurry. Proceedings of the 7th international conference exhibition on piling and deep foundations, Vienna, pp. $1 \cdot 6 \cdot 1-1 \cdot 6 \cdot 8$.

Majano, R. E. \& O’Neill, M. W. (1993). Effect of mineral and polymer slurries on perimeter load transfer in drilled shafts, Report UHCE-93-1. Houston, TX, USA: University of Houston.

Majano, R. E., O’Neill, M. W. \& Hassan, K. M. (1994). Perimeter load transfer in model drilled shafts formed under slurry. J. Geotech. Engng. 120, No. 12, 2136-2154.

Nash, K. L. (1974). Stability of trenches filled with fluids. J. Constr. Div. ASCE 100, No. 4, 533-542.

Ng, C. W. W. \& Lei, G. H. (2003). Performance of long rectangular barrettes in granitic saprolites. J. Geotech. Geoenviron. Engng., ASCE 129, No. 8, 685-696.

Peña Duarte, M. A. (2007). Foam as a soil conditioner in tunnelling: physical and mechanical properties of conditioned sands. DPhil thesis, University of Oxford, UK.

Randolph, M. F. (2003). Science and empiricism in pile foundation design. Géotechnique 53, No. 10, 847-875, http://dx.doi.org/ 10.1680/geot.2003.53.10.847.

Shakir, R. R. \& Zhu, J. (2010). An examination of the mechanical interaction of drilling slurries at the soil-concrete contact. J. Zhejiang Univ. - Sci. A (Appl. Sci. Engng) 11, No. 4, 294-304.

Suckling, T. P., Lam, C., Jefferis, S. A. \& Pantling, C. J. (2011). Evaluation of causes of bleeding of free water from a bentonite slurry. Proceedings of the 36th annual conference on deep foundations, Boston, pp. 401-407.

Tawfiq, K. \& Broughton, H. L. III (1996). Friction characteristics of cohesionless soil penetrated by polymer and mineral slurries. Proceedings of the 4th materials engineering conference, Washington, DC, vol. 2, pp. 1170-1178.

Thasnanipan, N., Baskaran, G. \& Anwar, M. A. (1998). Effect of construction time and bentonite viscosity on shaft capacity of bored piles. Deep foundations on bored and auger piles: Proceedings of the 3rd international geotechnical seminar on bored and auger piles, Ghent, Belgium (ed. W. F. Van Impe), pp. 171177. Rotterdam, the Netherlands: Balkema.

Thasnanipan, N., Aye, Z. Z. \& Boonyarak, T. (2003). Behaviour of polymer-based slurry for deep-seated bored piles in multilayered soil of Bangkok. In Deep foundations on bored and auger piles: Proceedings of the 4th international geotechnical seminar on bored and auger piles, Ghent, Belgium (ed. W. F. Van Impe), pp. 267-274. Rotterdam, the Netherlands: Millpress.

Tomlinson, M. J. (2001). Foundation design and construction, 7th edn. Harlow, UK: Pearson Education.

Troughton, V. M. (1992). The design and performance of foundations for the Canary Wharf development in London Docklands. Géotechnique 42, No. 3, 381-393, http://dx.doi.org/10.1680/ geot.1992.42.3.381.

Veder, C. (1953). Method for the construction of impermeable diaphragms at great depth by means of thixotropic muds. Proceedings of the 3rd international conference on soil mechanics and foundation engineering, Zurich, vol. 2, pp. 91-94 (in French).

Ventouras, K. \& Coop, M. R. (2009). On the behaviour of Thanet Sand: an example of an uncemented natural sand. Géotechnique 59, No. 9, 727-738, http://dx.doi.org/10.1680/geot.7.00061.

Wates, J. A. \& Knight, K. (1975). The effect of bentonite on the skin friction in cast-in-place piles and diaphragm walls. Proceedings of the 6th Regional Conference for Africa on Soil Mechanics and Foundation Engineering, Durban, vol. 1, pp. $183-188$. 